\title{
LÉXICO E ENSINO: UMA ANÁLISE DO USO DAS PREPOSIÇÕES MENOS FREQUENTES EM UM CORPUS DE APRENDIZES DE LÍNGUA ESPANHOLA
}

\author{
LEXICON AND TEACHING: AN ANALYSIS OF THE USE OF LESS \\ FREQUENT PREPOSITIONS IN A SPANISH LEARNERS CORPUS
}

Jéssyca Camargo da Cruz ${ }^{1}$

Celso Fernando Rocha ${ }^{2}$

\begin{abstract}
RESUMO: O presente artigo tem por objetivo apresentar o levantamento quantitativo e a análise do uso de preposiçóes menos frequentes (subuso) em um corpus de aprendizes de espanhol como língua estrangeira. Observamos o uso de contra, hacia, enfrente de, excepto e tras, por meio do instrumental da Linguística de Corpus, contrastando tal conjunto lexical com um corpus de apoio, composto pela gramática espanhola (normativa e descritiva) e um corpus de referência online de língua espanhola (CREA). Sendo assim, apresentamos análises efetuadas a partir de um corpus composto por 276 redaçôes (85.729 palavras), coletado junto a dois grupos universitários de primeiro ano dos cursos de Licenciatura e Bacharelado em Letras, durante o período de 2011 a 2013. O levantamento dos dados foi feito com o auxílio do software WordSmith Tools (versăo 6), cujas ferramentas WordList e Concord possibilitaram gerar uma lista de frequência das preposiçóes no corpus de estudo e analisar seus respectivos usos com base nas linhas de concordâncias. Com relaçâo aos dados coletados, observou-se instabilidade sintática no emprego das preposiçóes e, em alguns casos, nâo compreensâo dos aspectos semânticos relacionados ao léxico em tela.
\end{abstract}

Palavras-chave: Linguística de Corpus; corpus de aprendizes de espanhol; léxico e ensino.

ABSTRACT: This article aims at presenting a quantitative research and the analysis of the use of prepositions that are less frequent (underused) in a corpus of learners of Spanish as a foreign language. We have observed the use of contra, hacia, enfrente de, excepto and tras through Corpus Linguistics by contrasting this lexical set and a supplementary corpus, composed by normative and descriptive Spanish grammar and by an online reference corpus of Spanish (CREA). Therefore, we present analyses made on a corpus constituted by 276 writings ( 85.729 words), gathered from two groups of freshman Language/Letras students, from 2011 to 2013. The data were collected with the aid of the WordSmith Tools (version 6) software and its tools, WordList and Concord

Mestranda no Programa de Pós-Graduaçăo em Linguística e Língua Portuguesa, FCLAr - UNESPAraraquara.E-mail: jessycacamargo_esp@hotmail.com.

2 Professor Assistente Doutor, IBILCE - UNESP.E-mail: celsotrad@yahoo.com.br. 
enabled us to extract the frequency list of the prepositions in the corpus of study, as well as to observe and analyse their respective uses based on the lines of concordance. Concerning the data collected, we have observed some syntactic instability in the usage of prepositions and in some cases the non-comprehension of the aspects associated with the lexicon discussed.

Keywords: Corpus Linguistics; Spanish learners' corpus; lexicon and teaching.

\section{INTRODUÇÃO}

A palavra grega léxico significa dicionário, é empregada (de maneira mais geral) como sinônimo de vocabulário de uma língua, trazendo em seu cerne a ideia de conjunto de palavras que se relacionam. Estudar o léxico de uma língua é tentar compreender relaçōes que se estabelecem entre as palavras e as motivaçōes intrínsecas e extrínsecas ao funcionamento da língua que determinam padrôes de usos correntes.

Nesse sentido, um estudo com base em corpus possibilita a observaçăo, por meio das linhas de concordância, de itens lexicais específicos, em seus respectivos cotextos e contextos de uso (padróes coligacionais e padróes colocacionais). A associaçâo coligacional (coligaçấo: do latim cum ligare) estabelece como se dá a ligaçâo entre os elementos linguísticos (sintaxe e léxico). Trata-se da "ocorrência de uma classe gramatical ou padrăo estrutural com outro ou com uma palavra ou frase" (SINCLAIR, 2003, p. 173). No passado, havia definiçōes mais estanques sobre o que seria considerado uma coligaçâo (verbos seguidos por outros verbos, por exemplo). No presente, observa-se uma concepção mais ampla e irrestrita no que diz respeito à sintaxe e o léxico (SINGLETON, 2000).

Por seu turno, o aspecto colocacional (colocaçáo: do latim cum locus) determina que o léxico seja responsável por estabelecer as combinaçôes realizáveis, ou seja, assim que uma palavra é escolhida abre-se um leque de possibilidades maior ou menor em termos relacionais. Isto é, colocaçâo significa que há uso estatisticamente significativo de determinadas palavras acompanhadas de outras e, qualitativamente, observa-se, simultaneamente, o princípio da idiomaticidade. Para o falante monolíngue, as combinatórias estâo disponíveis na língua e sâo adquiridas muitas vezes de maneira automática, sem reflexăo. A fraseologia e a terminologia beneficiam-se substancialmente de tais dados estatísticos, uma vez que o reconhecimento desses padróes de uso sâo critérios para seleçâo lexical. Cabe mencionar que uma coocorrência (uma palavra ocorrendo ao lado de outra) năo é suficiente para determinar um padrăo colocacional, ou seja, entre léxico e campos semânticos.

No que se refere ao uso de corpora como ferramenta no ensino de língua estrangeira e metodologia de investigaçăo, nota-se que a Linguística de Corpus (doravante LC) conquistou um espaço significativo, a princípio, no âmbito do ensino de língua inglesa. Embora ainda encontremos um número expressivamente maior de estudos com corpora nessa área, principalmente para elaboraçăo de gramáticas e dicionários de inglês, atualmente contamos com estudos em LC em diversos idiomas, inclusive na área do espanhol. 
No contexto brasileiro de ensino de espanhol, por exemplo, o número de investigaçóes desenvolvidas vem crescendo. Na modalidade dissertaçăo de mestrado podemos citar os trabalhos já concluídos de: Jacobi (2001), Balbás (2003), Alonso (2006), Silva (2013), Serikaku (2014). No formato tese de doutorado temos como referência os estudos desenvolvidos por Bissaco (2010), Alonso (2013). Já no âmbito dos artigos publicados em periódicos encontramos textos que propóem uma reflexáo acerca do uso da LC no ensino de línguas, como por exemplo: Araújo Júnior (2014), Sebold e Maggessy (2014), Cabrera, Gómez e Jara (2014), Llanos (2014), Rocha (2013, 2014), Stein (2013), Bissaco (2013), Silva (2006), entre outros.

Desse modo, nossa proposta, neste artigo, difere-se dos trabalhos citados pelo fato de apresentarmos os dados e análises referentes ao emprego de cinco preposiçóes menos frequentes (subuso) em um corpus compilado a partir de textos produzidos por aprendizes de língua espanhola em ambiente universitário brasileiro.Mais especificamente, descreveremos o uso de contra, hacia, enfrente de, excepto e tras por meio do instrumental da LC, contrastando-o com a gramática espanhola (GE) (normativa e descritiva) e um corpus online de língua espanhola: Corpus de Referencia delEspañolActual (CREA). Simultaneamente, cotejaremos os dados levantados com os usos prescritos pela gramática brasileira (GB) (normativa e descritiva).

Apresentaremos os resultados preliminares de um estudo de maior envergadura a respeito do uso das preposiçôes em redaçōes de estudantes universitários dos cursos de Licenciatura em Letras e Bacharelado em Traduçăo. Trata-se de uma pesquisa de Mestrado, cujo objetivo é descrever as características dos textos produzidos pelos aprendizes de espanhol como língua estrangeira (ELE), dando maior ênfase ao uso das preposiçōes.

\section{ALGUNS CONCEITOS OPERACIONAIS}

A LC é uma área dos estudos da linguagem que se dedica à coleta, descriçăo e análise de corpus, por meio de programas de computador que auxiliam na organizaçâo de dados e extraçấo de amostragens linguísticas. Pode ser considerada uma abordagem que proporciona ao pesquisador analisar quantitativa e/ou qualitativamente uma grande quantidade de dados autênticos com o auxílio de ferramentas computacionais. A extraçâo desses dados linguísticos fornece evidências empíricas para o estudo de diversos fenômenos linguísticos (KINDERMANN, 2009).

Corpus, por sua vez, define-se como:

[...] um conjunto de dados linguísticos, podendo ser de característica oral ou escrito, organizado sistematicamente segundo determinados critérios, suficientemente extensos em amplitude e profundidade de modo que sejam representativos no total do uso da língua ou de algum aspecto linguístico que seja possível ser processados em computador com o objetivo de obter resultados diversos e úteis para descriçáo e análise da língua (SÁNCHEZ, 1995, p. 05).

Por seu turno, Viana (2010, p. 27) aponta algumas características definitórias essenciais de um corpus: (a) deve ser compreendido como um conjunto de textos; (b) contempla textos (orais ou escritos) que tenham sido efetivamente produzidos por 
falantes de determinada língua; (c) consiste numa forma de representar empiricamente o uso que se faz de uma língua em seu sentido geral ou específico; (d) é uma reproduçâo da produçăo linguística de toda a populaçăo que se quer investigar ou uma amostra representativa dessa populaçăo com base em princípios claros e bem definidos; (e) assume a forma eletrônica com vistas a ser investigado pelo computador; (f) é concebido com o objetivo de possibilitar a realizaçáo de uma pesquisa linguística.

Para Berber Sardinha (2004, pp. 20-21), a nomenclatura usada para definir os tipos de corpora é extensa e pode variar de acordo com o seu conteúdo e propósito. Os critérios considerados para cada tipologia de corpus sâo: modo, tempo, seleçăo, conteúdo, autoria, disposiçấo interna e finalidade. Para esta investigaçâo, utilizamos como objeto de estudo um corpus de aprendizes de espanhol, compilado diacronicamente e na modalidade escrita.

O corpus de aprendizes se diferencia das demais modalidades de corpora por se tratar de uma reuniâo de textos de autoria específica, isto é, de aprendizes de uma língua estrangeira (LE). Esses textos,via de regra, sâo produzidos em contexto específico, ou seja, no âmbito do ensino-aprendizagem de línguas, com o intuito de investigar aspectos da aquisiçăo de segunda língua (L2) ou LE de um grupo de aprendizes. Năo obstante, a linguagem do aprendiz também pode ser observada em outros ambientes naturais, como por exemplo, no entretenimento, na escola e no mundo real em geral. O aspecto mais importante que a LC privilegia, em suma, é a observaçâo da linguagem dos alunos de forma autêntica (BERBER SARDINHA, 2004, p. 269).

\section{O CORPUS UTILIZADO E A FORMA DE EXTRAÇÃO DOS DADOS}

O corpus de textos de aprendizes está composto por 744 redaçóes produzidas por alunos dos Cursos Bacharelado e de Licenciatura em Letras (aproximadamente 16 alunos por turma) e conta com 266.253 palavras e está arquivado, provisoriamente, no Departamento de Letras Modernas da UNESP, Campus de Sáo José do Rio Preto.

Na Tabela 1, a seguir, apresentamos alguns dados referentes ao corpus completo:

Tabela 1 - Temas propostos, indicação das turmas e total de palavras.

\begin{tabular}{c|c|c}
\hline Temas para o primeiro ano & Temas para o segundo ano & Temas para o terceiro ano \\
\hline Descrição pessoal & Descrição pessoal & Imigração \\
\hline Descrição de uma pessoa (laboratório) & Preservação do meio ambiente & As drogas \\
\hline Organização pessoal & A Internet & Sonhos \\
\hline Uma foto & Os sentidos & Familia \\
\hline A casa dos meus sonhos & Aprendizagem de espanhol \\
\hline Como seria a vida em marte & Enredo de novela & \\
\hline O zoológico & Descrição de uma cidade & A violência (laboratório) \\
\hline Descrição de uma cidade & Violência (laboratório) & \\
\hline A liberdade & Uma foto & \\
\hline Recordações de infância & Liberdade & \\
\hline Descrição de uma cidade (laboratório) & Uma foto (laboratório) & Total de Palavras: 35.251
\end{tabular}


A Tabela 1 apresenta os temas propostos para cada grupo. No caso do primeiro ano, foco do presente estudo, as redaçôes foram coletadas de grupos distintos (turma de 2011 e de 2013), no segundo ano, foram três turmas (2011, 2012 e 2013) e, para o terceiro ano, contamos com as redaçóes produzidas por apenas uma turma (2012).

Algumas das redaçôes foram feitas em laboratório, sem consulta a dicionários, Internet ou materiais de apoio. A intençâo foi contribuir para o aumento da heterogeneidade na construçăo dos corpora. Quanto à extensâo dos textos, foi pedido aos alunos que escrevessem redaçôes com no mínimo 300 e no máximo 500 palavras e as salvassem em formato "doc" (docx) - (Microsoft Office $\left.{ }^{\circledR}\right)$ - e "txt" (textos sem formataçâo). As redaçóes foram corrigidas (ou sublinhadas) e devolvidas em formato impresso (o corpus coletado nâo incorporou as correçóes efetuadas e discutidas em sala de aula).

Neste artigo, trataremos dos dados e análises efetuadas a partir do corpus composto por 276 redaçôes (85.729 palavras) coletado junto aos dois grupos do primeiro ano (2011 e 2013).

Com relaçăo à extraçâo dos dados, utilizamos o Word Smith Tools (WST), um dos programas mais utilizados para pesquisas em LC. Esse software, criado por Michael Scott, professor da Universidade de Liverpool, possui três ferramentas: WordList, Concord e Keywords. No desenvolvimento deste trabalho, empregamos as ferramentas WordList e Concord. A ferramenta WordList permitiu criar listas de palavras por ordem de frequência e por ordem alfabética e, por conseguinte, foi possível observar o léxico mais empregado no corpus.

Além das listas de palavras, a segunda ferramenta, a Concord, gerou listagens das ocorrências de itens específicos ou nódulos, acompanhados dos seus respectivos cotextos (texto ao redor da palavra), facilitando, assim, a identificaçáo de sequências maiores nos textos (colocaçôes).

Por meio do corpus de apoio (GE e GB) e do corpus de referência (CREA) levantamos e analisamos os elementos presentes nas linhas de concordâncias selecionadas. Cabe salientar que devido ao escopo do presente artigo, apresentamos algumas análises preliminares efetuadas.

As preposiçōes na gramática espanhola e na gramática brasileira: conceituaçōes introdutórias

Tradicionalmente, na gramática espanhola (GE), há certa tendência de classificaçâo dos advérbios, das conjunçôes e preposiçōes dentro da classe das partículas. A característica de nâo variaçâo morfológica desponta como elemento chave para tal inclusâo.

Segundo o Diccionario de la lengua española, a preposiçâo é uma palavra invariável que introduz elementos nominais ou oraçôes subordinadas substantivas, tornando-os dependentes de alguma palavra anterior. O valor semântico das preposiçóes pode variar, pois existem preposiçōes com significado próprio, outras com significado deduzido pelo contexto, e outras, sem significado léxico algum (TORREGO, 2005, p. 219).

Segundo Torrego (2005), as preposiçōes:

[...] constituem uma classe fechada de palavras. Săo palavras átonas; invariáveis, ou seja, năo possuem desinências; nunca podem agir com autonomia sintática, salvo quando aparecem em enunciados de caráter metalinguístico, nos quais atuam como substantivos e em algumas expressóes coloquiais. (2005, p. 218-219) 
Algumas gramáticas em espanhol dividem as preposiçôes entre simples e compostas (DUEN̂AS; HERMOSO, 2011). Fazem parte da lista de preposiçōes simples: a, ante, bajo, con, contra, de, desde, durante, en, entre, excepto/salvo, hacia, hasta, mediante, por, para, según, sin, sobre e tras. No que se refere ao segundo caso, sâo consideradas preposiçōes compostas: delante de, detrás de, debajo de, encima de, dentro de, fuera de, al lado de/junto a, enfrente de/frente a, alrededor de, cerca de, lejos de, antes de e después de.

Por seu turno, em língua portuguesa as preposiçōes sâo palavras que servem de subordinaçăo entre um termo e outro, tornando-os dependentes entre si. Sousa Lima (1948) classifica esses termos dependentes entre antecedentes e consequentes. Nos exemplos (a) livro de Pedro, (b) obediente a seus pais, e, (c) moro em Săo Paulo, as palavras de, a e em ligam entre si dois termos da frase, que vem respectivamente antes e depois delas. Os termos que precedem as preposiçôes (livro, obediente, moro) sâo termos antecedentes; os que seguem (Pedro, seus pais, Săo Paulo) săo os termos consequentes (SOUSA LIMA, 1945, pp. 38-39 apud LIMA, 2011, p.231).

As preposiçōes essenciais săo: a, ante, até, após, com, contra, de, desde, em, entre, para, por, perante, sem, sob, sobre. Em contrapartida, as preposiçôes consideradas por acidente sâo: exceto, durante, consoante, mediante, fora, afora, segundo, tirante, senăo, visto (LIMA, 2011).

O que a GE chama de preposiçôes compostas, a GB nomeia de locuçōes prepositivas. Tais locuçóes sâo assim denominadas devido à última palavra que as acompanham serem sempre preposiçōes, conforme podemos observar nos exemplos seguintes: ao lado de, antes de, além de, adiante de, a despeito de, acima de, abaixo de, depois de, em torno de, a par de, apesar de, através de, de acordo com, com respeito a, por causa de, quanto a, respeito a, junto a, em atençăo a, graças a, etc. (LIMA, 2011).

\section{O USO DAS PREPOSIÇÕES NOS TEXTOS DOS APRENDIZES}

Após a extraçâo das listas de palavras mais frequentes, selecionamos as cinco preposiçóes menos empregadas pelos aprendizes de ELE (subuso). A Tabela2, a seguir, apresenta o número de vezes em que as preposiçôes foram usadas pelos estudantes:

Tabela 2: Preposições menos frequentes

\begin{tabular}{c|c}
\hline Preposição & Frequência \\
\hline Contra & 9,00 \\
\hline Hacia & 9,00 \\
\hline Enfrentede & 4,00 \\
\hline Excepto & 3,00 \\
\hline Tras & 1,00 \\
\hline
\end{tabular}

A partir dos dados gerados pelo WST, passamos a analisar seus respectivos usos com base nas linhas de concordâncias. Apresentamos os dados dos corpora de textos de aprendizes do primeiro ano (turmas de 2011 e 2013). 


\section{O EMPREGO DE CONTRA}

Em língua latina o léxico em tela é empregado como advérbio e como preposiçăo. Como advérbio tem o sentido de "face-a-face", defronte ou em frente, enquanto que seu uso como preposiçâo apresenta o sentido de oposiçâo e luta (p. ex.contra naturam). Em língua espanhola, expressa tanto a oposiçăo material como nâo-material e năo admite o uso de "que" no caso de locuçôes conjuntivas (cf. Moliner, 2008). Também sâo frequentes alguns usos específicos, contendo a preposiçăo "en" (votar en contra / ir en contra de algo), náo registrado no corpus.

Por meio do WST foi possível localizar parágrafos contendo a palavra contra e extraí-los na integra. A seguir, apresentamos as linhas de concordância ampliadas:

\section{Quadro 1: Linhas de concordância ampliada para contra ${ }^{3}$}

\begin{tabular}{|c|c|}
\hline Linha & Excerto ${ }^{8}$ \\
\hline 01 & $\begin{array}{c}\text { La casa de mis sueños, la imagino en una ciudad llena de árboles, con poco atasco, que no sea muy } \\
\text { caliente en el verano, ni mucho fría en el invierno, que florezca con muchos colores en la primavera y que } \\
\text { en el otoño en las calles si queden hojas marrones y los árboles desnudas permitan ver las nubes blancas } \\
\text { contrastaren con el cielo azul y las estrellas brillantes contra el cielo nocturno. } \\
\text { (Redação sobre a Casa dos Sonhos) }\end{array}$ \\
\hline 02 & $\begin{array}{l}\text { Un grupo de esclavos fugitivos se unió con los mutantes descontentes con el sistema y en alto del monte } \\
\text { Olimpo, organizaron una revolución para luchar contra los opressores. } \\
\text { (Redação sobre Como seria a vida em Marte) }\end{array}$ \\
\hline 03 & $\begin{array}{l}\text { Pero la libertad para el mundo masónico es el Hombre, que rige contra la voluntad de Dios por un ejercicio } \\
\text { de su libre voluntad, por esto, no es mas el Divino lo centro de lo mundo pero si los hombres, y la iglesia } \\
\text { dice que cuando los hombres se tornase libres recae sobre él y sobre toda su posteridad la Justicia divina. } \\
\text { (Redação sobre A liberdade) }\end{array}$ \\
\hline 04 & $\begin{array}{r}\text { Es posible también que hayan grupos revolucionarios } \\
\text { muy grandes que intentarán de } \\
\text { (Redação sobre Como se }\end{array}$ \\
\hline 05 & $\begin{array}{r}\text { Los hombres invadirán el planeta y habrá una gran guerra contra lc } \\
\text { mantener la libertad, pero las fuerzas espaciales de la Tierra son } \\
\text { (Redação sobre Como seria a vida el }\end{array}$ \\
\hline 06 & $\begin{array}{l}\text { Rien alto para expulsar el dolor del alma, no sé si es porque aquí reina la dicha, o si son tan solitários que lo } \\
\text { mejor que pueden hacer es sonreir, como si fuera un escudo contra la desdicha. } \\
\text { (Redação sobre Como seria a vida em Marte) }\end{array}$ \\
\hline 07 & $\begin{array}{l}\text { Yo compreendo la necesidad de que todos usen el uniforme, pero obrigar el alumno a usar-lo es } \\
\text { inconstitucional! Es contra la leye! Yo podria ter nascido en una familia de nazistas y ter sido educada por } \\
\text { ellos. Creo que dava igual, o mejor: Por lo menos con ellos yo saberia que estou siendo comandada. } \\
\text { (Redação sobre A liberdade) }\end{array}$ \\
\hline 08 & $\begin{array}{l}\text { El hombre con ropa rota y un sombrero para tratar de protegerse del sol, con barba y ojos ausentes, casi } \\
\text { muerto de hambre, luchando contra la sequía todos los días (días) } \\
\text { (Redação sobre Uma foto) }\end{array}$ \\
\hline 09 & $\begin{array}{l}\text { un grande prejuicio social contra los nordestitos pobres. } \\
\text { ação sobre Como seria a vida em Marte) }\end{array}$ \\
\hline
\end{tabular}

3 Os trechos apresentados foram retirados dos corpora eletrônicos e encontram-se transcritos na íntegra, sem correçấo ortográfica ou sintática. Também náo indicaremos, por questăo de confidencialidade, as turmas das quais os parágrafos foram extraídos. Por seu turno, as correçōes foram feitas nas redaçóes impressas, devolvidas e discutidas em sala de aula com os alunos. Paralelamente, foi efetuado um trabalho de enriquecimento léxico, os achados relatados neste artigo foram compartilhados com as turmas, o que aumentou significativamente a conscientizaçăo sobre os fenômenos linguísticos levantados. 
Em termos gerais, observa-se que há o uso precedido de sintagma nominal ou verbal (luchar, ser, regir, etc.) e seguido de sintagma nominal (la ley, la desdicha, los cambios, etc.). Por sua vez, năo houve registro de en contra.

Na linha 01, observa-se a descriçăo do entorno de uma casa, o uso de contra acompanhado de sintagma nominal e sem precedente verbal próximo (parece-nos que o verbo ver faria parte das duas construçóes subsequentes e seria regido pelo verbo contrastar). Há questōes de construçâo do parágrafo e aspectos relacionados à progressâo de ideias que foram discutidas com a turma após a análise dos excertos. 0 primeiro aspecto a ressaltar é a regência do verbo contrastar em espanhol. Em levantamento efetuado no CREA observamos ocorrência de usos com as preposiçôes con/a e usos como verbo intransitivo (los colores contrastan agradablemente). Em língua latina, por sua vez, este verbo é construído com a preposiçăo contra e o verbo sto (estar de pé, estar levantado). Argumentamos, por conseguinte, que o uso contrastar contra trata-se de pleonasmo, tanto em língua espanhola quanto em língua portuguesa. A substituiçâo de contra por con na última oraçăo do excerto 01 resolveria adequadamente a questăo de regência e contribuiria simultaneamente para o aumento da coesâo por meio do paralelismo sintático (repetiçâo da preposiçăo con).

Em 02 e em 04, há o uso do verbo luchar, adequadamente regido pela preposiçăo contra. Verificam-se, também, inadequaçōes gramaticais e ortográficas que foram encaminhadas por meio das discussōes em sala.

0 excerto 03 apresenta o verbo regir que pode ser transitivo (esta ley rige el mercado) ou intransitivo (ya no rige esta ley). A construçăo rige contra năo registrou ocorrências no CREA. Como sugestâo ao grupo, propusemos a busca da construçâo en contra de em contextos do CREA. Houve surpresa entre os aprendizes ao constatarem que o corpus online gerou mais de 6 mil ocorrências da construçâo mencionada. Houve conscientizaçấo de que a colocaçăo era facilmente reconhecida e, por outro lado, nunca a haviam empregado.

Os trechos 05 e 06 apresentam construçōes nominais após contra (contra los marcianos e contra la desdicha).

No número 07, houve uma discussăo maior com o grupo no sentido de problematizar o uso da expressâo es contra la ley. Sugerimos buscas na web e no CREA para o binômio es contra x está en contra. Os alunos observaram que há mais uso para a segunda construçâo (mais de um milhăo na web) do que para a primeira (duzentas mil). Também verificaram que no caso da combinaçâo mais frequente há tendência de sujeito explícito na oraçâo, (por exemplo: Pedro está en contra del cambio; Francia está en contra de la guerra; la población está en contra de la invasión) e que quando há o verbo ser, houve mais casos com antecedentes abstratos (la situación, ideas, eso etc.).

Nos dois últimos casos fizemos apenas algumas correçōes ortográficas e de sintaxe, uma vez que o uso de contra está adequado.

\section{O EMPREGO DE HACIA}

A preposiçăo hacia possui usos específicos em língua espanhola e pode apresentarse com diferentes sentidos dependendo de sua funçâo sintática. Por se tratar de um 
léxico com várias traduçóes para o português, a assimilaçăo de suas diversas acepçōes pelo aprendiz brasileiro envolve trabalho intenso em sala de aula.

Em resumo, hacia atua com os sentidos de direçăo, movimento ou orientaçấo a algum ponto. Em alguns casos, pode ser substituída pela preposiçăo a. Ex.: Se dirige hacia (a) la casa de su padre. Ademais, se usa hacia quando se deseja expressar localizaçáo temporal aproximada. Neste caso, hacia é sinônimo de alrededor de/cerca de/ aproximadamente.Ex.: Te llamo hacia las 3 h de la tarde. Por fim, esta preposiçấo também pode expressar sentimento com relaçăo a algo ou alguém, como p. ex: Su antipatia hacia los médicos es casi malsana.

A seguir, apresentamos o Quadro 2 com os usos de hacia no corpus de aprendizes:

Quadro 2: Linhas de concordância ampliada para hacia

\begin{tabular}{|c|c|}
\hline Linha & Excerto \\
\hline 01 & $\begin{array}{l}\text { A la derecha hay una ventana que da hacia afuera. } \\
\text { (Redação sobre a Casa dos Sonhos) }\end{array}$ \\
\hline 02 & $\begin{array}{c}\text { Mientras el fondo del castillo en las montañas alpinas, con colores blanca y gris - transmitido soledad } \\
\text { y tristeza; vivia un hombre que nunca miraba el sol, porque sus ojos azules no podría con los rayos del } \\
\text { "astro", por eso, solo salía en las noches de su casa donde miraba las estrellas y hacia tambien pedía } \\
\text { para las estrellas cadentes que algún día ponese algo en su corazón que lo acalentase. } \\
\text { (Redação sobre a Casa dos Sonhos) }\end{array}$ \\
\hline 03) & $\begin{array}{l}\text { Pero continuando con por el recorrido hacia adelante pasamos por una puerta que nos lleva al comedor, } \\
\text { donde hay una mesa de madera toda tallada a mano, y sus doce sillas también. } \\
\text { (Redação sobre a Casa dos Sonhos) }\end{array}$ \\
\hline 04 & $\begin{array}{c}\text { Al lado hay un elevador para el segundo piso y después una escalera muy elegante que nos lleva hacia } \\
\text { arriba también. } \\
\text { (Redação sobre a Casa dos Sonhos) }\end{array}$ \\
\hline 05 & $\begin{array}{c}\text { Me puse muy celosa, pues toda mi atención se volvió hacia mi pequeño hermano. } \\
\text { (Redação sobre Recordações de Infância) }\end{array}$ \\
\hline 06 & $\begin{array}{c}\text { Vamos a volver hacia dentro y subir las gradas, ya vemos una pequeña sala con algunos sillones, y } \\
\text { algunos almuadones en el piso, podemos ver una tele, un dvd, un videojuego, hay muchas ventanas. } \\
\text { (Redação sobre a Casa dos Sonhos) }\end{array}$ \\
\hline 07 & $\begin{array}{l}\text { Si continuas mas al frente verás un corredor que te lleva hacia la cocina, comedor y al piso de arriba. } \\
\text { (Redação sobre a Casa dos Sonhos) }\end{array}$ \\
\hline 08 & $\begin{array}{c}\text { Cuando sales a caminar por las calles, puedes oir los autos pasando, los perros ladrando y escuchas } \\
\text { también los microbuses gritando: HACIA LA CALLE CALACOTO, SAN MIGUEL Y ACHUMANI.!!!!, es un } \\
\text { poco irritante sonido al principio, pero después de un tiempo ni lo escuchas mas. } \\
\text { (Redação sobre Uma Cidade - feita em laboratório) }\end{array}$ \\
\hline 09 & $\begin{array}{c}\text { Com la gran explosión demográfica de la Tierra, la humanidad tendrá que buscar nuevos sitios para vivir, } \\
\text { entonces tendremos un gran desarrollo em las atividades espaciales y la construcción de modernas } \\
\text { naves que viajarán hacia el planeta Marte } \\
\text { (Redação sobre Como seria a vida em Marte) }\end{array}$ \\
\hline
\end{tabular}

A preposiçăo hacia teve nove ocorrências no corpus e se encontra na lista de preposiçôes em subuso. Na maioria dos casos essa preposiçăo foi empregada como sinônimo de em direçâo de. É interessante notar que nâo houve nenhum caso de uso de hasta ao invés de hacia, o que normalmente pode ser um tema de dificuldade para os aprendizes. No entanto, vemos um subuso do emprego de hacia com as demais funçôes que esta preposiçăo pode exercer.

Cabe acrescentar que no excerto 02 há uso desnecessário de hacia, deslocado e sem conexăo com o contexto. 


\section{EMPREGO DE ENFRENTE DE/FRENTE A}

Em espanhol, o léxico frente significa fronte (parte superior do rosto situada em cima das sobrancelhas) ou o lado anterior de um edifício (fachada). Este vocábulo apresenta-se acompanhado da preposiçấo a quando se deseja expressar a açâo de estar diante ou em frente de algo ou alguém. Por outro lado, a palavra frente, unida à preposiçáo en, transforma-se em enfrente e deve ser usada combinada com a preposiçáo de. Assim, a gramática espanhola classifica o par enfrente de/ frente a como locuçâo preposicional (DUENAS; HERMOSO, 2011, p. 2009).

Observemos, no Quadro 3, os excertos com o emprego de (en)frente:

Quadro 3: Linhas de concordância ampliada para enfrente de eoutras construções

\begin{tabular}{|c|c|}
\hline Linha & Excertos \\
\hline 01 & $\begin{array}{l}\text { Por último, mi tío Rogério (padre de Dalila y Artur) está en frente de mi prima, jugando con un juguete. } \\
\text { (Redação sobre Uma foto) }\end{array}$ \\
\hline 02 & $\begin{array}{l}\text { En São José de rio preto casi no hay actividades culturais, por eso, hay muchas criticas ao alcalde, } \\
\text { algunas persons aquedaranse en frente de la alcalderia por horas... } \\
\text { (Redação sobre Uma Cidade - feita em laboratório) }\end{array}$ \\
\hline 03 & $\begin{array}{c}\text { Él tendría una cama doble, en frente de la cama tendría un televisor y detrás de la televisión uma mesa } \\
\text { de estudio, que tendría mi computadora portátil, algunas fotos, y una estantería de pared con mis libros } \\
\text { favoritos. La ventana de mi habitación sería grande y tenía una vista de la casa del fondo. } \\
\text { (Redação sobre a Casa dos Sonhos) }\end{array}$ \\
\hline 04 & $\begin{array}{c}\text { El garaje estaría em frente de casa y del lado tendría um (un) jardín. Tan pronto como se abrió la puerta } \\
\text { que se ve una escalera al frente, que se llevaría en la parte superior de la casa. (que llevará a la parte } \\
\text { superior...) } \\
\text { (Redação sobre a Casa dos Sonhos) }\end{array}$ \\
\hline 05 & $\begin{array}{l}\text { A frente hay una plaza de alimentación con muchas personas almuerzando, yo hice una cara triste diante } \\
\text { de llas y me dieron un bocadillo... Comilo y maté mi hambre. } \\
\text { (Redação sobre a Casa dos Sonhos) }\end{array}$ \\
\hline 06 & $\begin{array}{c}\text { A la derecha estará uma escalera y abajo un camino de piedras que llevará a una puerta de vidro } \\
\text { adornada de vidrieras que quedará al fondo de la casa. A la frente habrá el comedor, que tendrá una } \\
\text { mesa grande }[\ldots] \\
\text { (Redação sobre a Casa dos Sonhos) }\end{array}$ \\
\hline 07 & $\begin{array}{c}\text { À derecha, una habitación para las visitas, à frente, una habitación doble y más al lado dos habitaciones } \\
\text { para los futuros hijos; } \\
\text { (Redação sobre a Casa dos Sonhos) }\end{array}$ \\
\hline 08 & $\begin{array}{c}\text { [...] vemos coches aparcados en las garajes, los niños jugando en frente a sus casas, padres y madres, } \\
\text { hermanos y amigos charlando sobre sus planes para su futuro y para el futuro de sus hijos... } \\
\text { (Redação sobre Uma Cidade - feita em laboratório) }\end{array}$ \\
\hline 09 & $\begin{array}{l}\text { Estamos a la frente del pizzara y allí no hay nada escrito. } \\
\text { (Redação sobre Uma foto) }\end{array}$ \\
\hline 10 & $\begin{array}{l}\text { El garaje estaría em frente de casa y del lado tendría un jardín. } \\
\text { (Redação sobre Como seria a vida em Marte) }\end{array}$ \\
\hline
\end{tabular}

Nas linhas 01 à 04, nota-se o desejo dos autores em expressar que $\mathrm{X}$ estava diante de Y, como em: Rogério está enfrente de mi prima; algunas personas se quedaron enfrente de la alcaldía; enfrente de la cama; enfrente de casa. Embora haja outros detalhes a serem discutidos com os alunos para os devidos encaminhamentos, os usos de enfrente de estâo adequados. Náo obstante, a combinaçăo en frente de apresenta um padrâo de frequência menor em comparaçăo com enfrente de. A respeito disso, a RAE propóe a escrita de enfrente como uma única palavra, mas também considera adequada segunda opçăo. Desse modo, parece-nos importante ressaltar essa questăo aos 
alunos, alertando-os desse dado e fazendo-os saber que as duas formas săo corretas, apesar de uma ser mais frequente que a outra.

A partir do excerto 05 encontramos possíveis sinais de interferência da língua materna (LM), bem como de associaçăo inadequada. 0 excerto 05 indica interferência da LM, devido à construçâo portuguesa "à frente". Como é sabido, diferentemente do que ocorre em língua portuguesa, a contraçăo entre artigo definido feminino e preposiçấo a năo ocorre no espanhol, o aluno retirou a crase e usou somente a preposiçăo. Essa hipótese se confirma no excerto 07, no qual outro aprendiz descreve que à frente do quarto de visitas há outro quarto de casal. Cumpre salientar que em português "estar à frente de algo" significa comandar algo, material ou figurativamente. $O$ equivalente dessa forma em espanhol seria estar al frente.

Na linha 06 o aprendiz descreve uma casa com uma escada situada à direita. No entanto, no momento de narrar que embaixo das escadas haverá um caminho que levará a uma porta de vidro e, que em frente a essa porta haverá uma sala de jantar com uma mesa grande, emprega a la frente que năo se refere à localizaçăo e, sim, ao substantivo frente (testa). Neste caso a associaçáo de "à frente" năo corresponde ao sentido que o aprendiz queria dar ao dizer que frente a la puerta de vidro haverá uma sala de jantar. O que provavelmente ocorreu foi a traduçăo literal de "à frente" para a la frente, pois em espanhol năo há contraçâo do artigo definido feminino (a) com a preposiçấo a, como ocorre com a crase em português. 0 excerto 09, apresenta o mesmo caso de inconsistência de emprego: com locuçăo preposicional enfrente de e substantivo frente.

Na linha 08, o aprendiz utilizou a combinaçăo en frente apara explicar que os meninos estavam brincando diante de sua casa, na qual os pais, irmáos e amigos conversavam sobre os planos para o futuro das crianças. As gramáticas do espanhol apresentam como locuçáo prepositiva os pares enfrente de ou frente a quando se deseja expressar o sentido de um ponto que mira a outro ponto. Entretanto, embora em uma frequência menor, a forma enfrente a, como sinônimo de enfrente de, pode ocorrer em determinadas variedades linguísticas, como no exemplo extraído pelo CREA: ¿Usted ya ha visto a la mujer que vende los aguacates no pales enfrente a las alchichonería?

Nesses casos, é importante que o professor discuta em sala de aula sobre a heterogeneidade do espanhol e esclareça aos alunos que algumas formas săo usadas em determinados contextos, os quais podem determinar a formalidade ou informalidade dos interlocutores.

Outro caso em que o uso de enfrente pode gerar dúvidas é quando estiver assumindo a funçáo do verbo enfrentar, cuja regência exige a preposiçáo a, como podemos observar no exemplo extraído do CREA: [...] da clases allí y Eliseo y éltuvieron la idea de enfrentar a los alumnos de producción y a los de [...].

No excerto 10, do Quadro 3, frente aparece acompanhado da preposiçấo em, podendo ser outro sinal de interferência da LM.

\section{O EMPREGO DE EXCEPTO}

A preposiçấo excepto provém da palavra latina exceptus e tem o sentido de exclusăo de um elemento que faz parte de um conjunto de ideias ou açôes expressadas anteriormente na sentença. 
Abaixo, apresentamos os excertos dos usos de excepto nas redaçóes sobre a Casa dos Sonhos e Recordaçōes de Infância.

Quadro 4: Linhas de concordância ampliada para Excepto e outras construções

\begin{tabular}{c|c}
\hline Linha & Excerto \\
\hline 01 & $\begin{array}{r}\text { Uno de los momentos más esperados del año (excepto la Navidad, en que yo esperaba ansiosamente } \\
\text { para abrir los regalos) era el día para comprar los útiles escolares. } \\
\text { (Redação sobre Recordações de Infância) }\end{array}$ \\
\hline 02 & $\begin{array}{r}\text { Esta puerta dá en el baño de la habitacion, todo blanco, excepto por las toallas rojas. } \\
\text { (Redação sobre a Casa dos Sonhos) }\end{array}$ \\
\hline 03 & Esta tiene una cama grande, predominantemiente negra - excepto por las dos almohadas. \\
(Redação sobre a Casa dos Sonhos)
\end{tabular}

Podemos observar que nos três excertos o uso de excepto tem o sentido de exceçăo, exclusăo. Na linha 01, o aluno expressa que o momento mais esperado do ano era o de comprar o material escolar, porém reitera que apesar de tudo, o natal ainda era o momento mais emocionante do ano. Ou seja, o autor do texto exclui dos momentos mais importantes do ano o natal, pois essa data é sem dúvida a mais esperada por ele, por ser o momento de abrir os presentes, conforme a tradiçăo brasileira. Náo obstante a primeira leitura, a construçấo entre parênteses, por outro lado, parece-nos deslocada (ou agramatical) por carecer de elementos linguísticos que permitam a recuperaçâo de sentido coesivo entre momento e navidad.

Na linha 02, menciona-se uma porta que dá acesso a um banheiro do quarto de uma casa. $\mathrm{O}$ aluno introduz a sentença descrevendo que essa parte da casa, assim como todos os objetos que encontramos nele, tem a cor branca. Porém, logo após mencionar essa característica usa a preposiçăo excepto que, por sua vez, contrapóe a ideia do todo branco, pois há toalhas vermelhas que se destacam entre a brancura descrita.

Na linha 03, vemos o mesmo sentido de um todo com uma única cor, no caso a cama que era predominantemente preta, com exceçâo dos travesseiros, cujas cores nâo sâo mencionadas, mas que podemos entender pelo uso de excepto que elas nâo eram pretas como a cama.

No que se refere ao emprego de excepto, podemos concluir que os usos foram adequados (exceto no primeiro caso) em língua espanhola.

\section{O EMPREGO DE TRAS}

A preposiçâo tras provém da palavra latina trans, que em espanhol significa al otro lado de, más allá de. O sentido dessa preposiçăo pode variar de acordo com o contexto de uso ou do elemento que a acompanhar (outra preposiçấo ou um verbo). Quando atua com o sentido de tempo ou espaço tem por sinônimos os advérbios detrás ou después de respectivamente, como p.ex.: (a) Hay um misterio escondido tras su aparente indiferencia, (b) Tras unos minutos de silencio, se reanudó la sesión. Em contrapartida, a preposiçâo tras ou a locuçáo tras de, quando estâo acompanhadas de um verbo no infinitivo podem apresentar o sentido de además de, encima de. Geralmente está posta antes de um substantivo ou adjetivo, p. ex.: Tras decir que era inocente pretendía que lo creyéramos (BRUYNE, 1999, p.695). 
A seguir, apresentamos a linha de concordância ampliada com o uso de tras, presente no corpus de aprendiz.

Quadro 5: Linha de concordância ampliada para tras

\begin{tabular}{c|c}
\hline Linha & Excerto \\
\hline \multirow{3}{*}{01} & El teatro municipal se encuentra situado próximo a la Famerp (Facultad de Medicina de Rio Preto) \\
& y al hospital HB, alrededor es un lugar simples y ligeramente ruidoso debido a los sonidos de los \\
& coches por las vías próximas, pero dentro es realmente un local mágico, con distintas pinturas en \\
& las paredes. De tras de su cortina encarnada el mundo se cambia y las colores monótonas dan \\
& $\begin{array}{c}\text { lugar al mundo de la fantasía y diversión. } \\
\text { (Redação sobre Uma Cidade) }\end{array}$ \\
\hline
\end{tabular}

A preposiçăo tras foi a menos frequente nesse corpus, apresentando uma única ocorrência. A partir do tema "Uma cidade" o aluno descreve a localizaçăo do teatro municipal, que se encontra próximo a uma faculdade e a um hospital. Menciona que os arredores do teatro sâo simples e que as ruas próximas sâo ruidosas, devido ao fluxo contínuo de carros. Entretanto, apesar dos detalhes que poderiam ofuscar toda a beleza de um teatro municipal, expressa que o interior é um lugar mágico, com diferentes pinturas nas paredes e que atrás das cortinas, ou seja, no palco, no momento da encenaçáo, o mundo se transforma em fantasia e diversăo. Nesse excerto, năo cabe dúvidas de que o trás foi usado com o sentido de detrás, tratando-se, portanto, de uma falsa ocorrência, devido à inadequaçâo ortográfica, pois nâo se trada de uma preposiçâo composta.

\section{OBSERVAÇÕES FINAIS}

Os dados levantados apontam para a necessidade de se levar ao aprendiz de língua espanhola atividades mais aprofundadas e pautadas em exemplos reais de emprego das preposiçóes mencionadas, uma vez que a maior parte do material disponível ao estudo deste tópico gramatical carece de contraste entre a língua portuguesa e a língua espanhola e, năo menos importante, exibe lacunas informacionais substanciais, no que diz respeito aos usos menos frequentes deste item lexical.

Nesse sentido, a ausência de descriçăo pode ser superada por meio do arcabouço teórico-metodológico da LC, tendo em vista que seu instrumental evidencia e desvela aspectos náo descritos nas gramáticas tradicionais (tanto em língua portuguesa quanto em língua espanhola).

Optamos, dado o escopo deste artigo, apresentar uma análise centrada na produçâo escrita de aprendizes universitários, tendo como corpora de apoio textos produzidos por falantes nativos (p. ex.: CREA). No entanto, ao professor de ELE, a possibilidade de aprofundamento por meio de corpora online, ou compilados exclusivamente para extraçăo e análise de dados linguísticos, configura-se como pedra de toque para apreensâo dos hiatos informacionais que dificultam o ensino-aprendizagem.

Corpora menores, com textos específicos (técnicos, literários, jornalísticos etc.) podem ser utilizados na construçáo de corpora, explicitando questóes relacionadas ao léxico mais ou menos frequente. Também é possível o ensino do instrumental da LC aos alunos, fomentando, sobremaneira, a autonomia na confecçâo e revisāo de textos. 
Além dos dicionários, gramáticas e explicaçōes do professor, mais uma janela privilegiada se abre em direçấo ao uso competente do idioma estrangeiro.

Por fim, mencionamos que o presente artigo é um desdobramento de uma pesquisa de mestrado em andamento e buscou descrever, por meio do arcabouço teórico-metodológico da LC, o emprego do léxico menos frequente em corpus de aprendizes de ELE.

É importante reafirmar que aliar o emprego do instrumental da LC às discussōes em sala de aula, bem como a refacçáo textual é um exercício eficaz no tratamento de questóes relacionadas ao uso do léxico. Pretendemos, em outras etapas de desenvolvimento do estudo, aprofundarmo-nos na descriçâo do uso do léxico mais frequente. Esperamos que as análises aqui apresentadas possam subsidiar novos estudos na área da LC, além de fomentar estudos contrastivos entre português e espanhol. 


\section{REFERÊNCIAS}

ALONSO, M. C. G. P. Corpus linguístico e a aquisiçăo de falsos cognatos em espanhol como língua estrangeira. Sáo Paulo: PUC-SP, 2006. 253 f. Dissertaçăo (Mestrado em Linguística Aplicada e Estudo da Linguagem), LAEL, Universidade Católica de Sáo Paulo, Sáo Paulo, 2006.

Ensino-aprendizagem de léxico em espanhol como língua estrangeira (E/LE) por meio de corpora (as palavras polissêmicas nos livros didáticos). Sáo Paulo: PUC-SP, 2013. 523 f. Tese (Doutorado em Linguística Aplicada e Estudo da Linguagem), LAEL, Universidade Católica de Sáo Paulo, São Paulo, 2013.

ARAUUJO JÚNIOR, B. J. As construçôes com SE na produçăo escrita de brasileiros aprendizes de espanhol como língua estrangeira: um estudo baseado em corpus. Letras \& Letras, [S.l.], v. 30, n. 2, pp. 64-81, dez. 2014. ISSN 1981-5239. Disponível em: <http://www.seer. ufu.br/index.php/letraseletras/article/view/27834>. Acesso em: 16 de jun. 2016.

BALBÁS, M. S. Análise de erros, baseada na Linguística de Corpus, da escrita de aprendizes brasileiros universitários de Espanhol como Língua Estrangeira. Sáo Paulo: PUCSP, 2003. 147 f. Dissertaçăo (Mestrado em Linguística Aplicada e Estudo da Linguagem), LAEL, Universidade Católica de São Paulo, São Paulo, 2003.

BERBER SARDINHA, T. Linguística de Corpus. Barueri: Manole, 2004.

BISSACO, C. M. Ensinando com corpora: mediaçáo e interaçáo em aulas de espanhol como língua estrangeira. Sáo Paulo: PUC-SP, 2010. 273 f. Tese (Doutorado em Linguística Aplicada e Estudo da Linguagem), LAEL, Universidade Católica de Săo Paulo, Sáo Paulo, 2010.

Linguística de Corpus: ferramentas para o ensino de heterossemânticos. Revista Eletrônica de Divulgaçăo Científica em Língua Portuguesa, Linguística e Literatura Letra Magna. Ano 09, n. 17, 2013.

BRUYNE, J. Las preposiciones. In: Gramática descriptiva de la lengua española. Madrid: Espasa, 1999, pp. 661-703.

CABRERA, A. F.; GÓMEZ, J. E.; JARA, A. V. Análisis de Errores Asistido por Computador basado en un Corpus de Aprendientes de Español como Lengua Extranjera. Revista Signos, Valparaíso, v. 47, n. 86, pp.385-411, dez. 2014. Disponível em: http://www.scielo. cl/pdf/signos/v47n86/a03.pdf. Acesso em: 01 de out. 2016.

DUEN̂AS, C. R.; HERMOSO, A. G. Gramática del español lengua extranjera. Madrid: Edelsa, 2011.

FERNANDES, F. Dicionário de verbos e regimes. 43 ed. Săo Paulo: Editora Globo, 1999.

GRANGER, S. Computer Learner Corpora, Second Language Acquisition and Foreign Language Teaching.Amsterdam/Philadelphia: John Benjamins, 2002.

JACOBI, C. Linguística de Corpus e ensino de espanhol a brasileiros: descriçáo de padrōes e preparaçáo de atividades didáticas (decir/hablar; mismo; mientras/ encuanto/ aunque).Săo Paulo: PUC-SP, 2001. 131 f. Dissertaçăo (Mestrado em Linguística Aplicada e Estudo da Linguagem), LAEL, Universidade Católica de Săo Paulo, Sâo Paulo, 2001. 
KINDERMANN, C. A. E. Corpora de aprendizes: uma ferramenta para o ensino de língua inglesa e formaçăo do futuro professor. Veredas On-line: Linguística de Corpus e Computacional, Juiz de Fora, v. 13, n. 2, pp.36-49, fev. 2009. Disponível em: <https:// veredas.ufff.emnuvens.com.br/veredas/article/view/288>. Acesso em: 20 fev. 2016.

LLANOS, Leonardo Campillos. Errores léxicos en el español oral no nativo: análisis de la interlengua basado en corpus. Elua, n. 28, pp. 85-124, 2014. Disponível em: http://rua. ua.es/dspace/handle/10045/48502. Acesso em: 01 out. 2016.

LAVID, J. Lenguaje y nuevas tecnologías. Nuevas perspectivas, métodos y herramientas para el lingüista del siglo XXI. Madrid: Cátedra, 2005.

LIMA, C. H. R. Gramática normativa da língua portuguesa. 49. ed. Rio De Janeiro: José Olympio, 2011. pp. 231-233.

MOLINER, M. Diccionario electrónico de uso del español. Madrid: Editorial Gredos, 2008.

REAL ACADEMIA ESPAÑOLA. Corpus de Referencia del Español Actual (CREA). Disponível em: 〈http://corpus.rae.es/creanet.html〉. Acesso em: 12 jun. 2016.

Diccionario de la lengua espańola. Disponível em: <http://corpus.rae.es/creanet. html . Acesso em: 12 jun. 2016.

ROCHA, C. F. O léxico em textos de aprendizes de língua espanhola: um estudo descritivo pautado na linguística de corpus como subsídio para o ensino. Estudos Linguísticos, Sâo Paulo, v. 1, n. 40, pp. 284-300, 2013.

Coleta de corpus de aprendizes: questôes qualitativas em uma pesquisa sobre a escrita de aprendizes de língua espanhola. Estudos Linguísticos, Sâo Paulo, v. 1, n. 43, pp. 286-297, 2014.

SÁNCHEZ, A. Definición e historia de los corpus», en: Sánchez, A., et al. (ed.), CUMBRE Corpus lingüístico del español contemporáneo. Madrid: SGEL, 1995.

SCOTT, M. WordSmith Tools.Version 6.Oxford: Oxford University Press, 2015.

SEBOLD, M.M.R.; MAGGESSY,A. K.E. Contextos de ocorrência das perífrases de gerúndio e particípio no português do Brasil e na variedade do espanhol do México e sua significaçăo aspectual. Letras \& Letras, [S.l.], v. 30, n. 2, p. 261-290, dez. 2014. ISSN 1981-5239. Disponível em: 〈http://www.seer.ufu.br/index.php/letraseletras/article/view/27981〉. Acesso em: 20 jun. 2016.

SILVA, I. M. 3., 2006, Rio de Janeiro. Actas del III simposio internacional José Carlos Lisboa de didáctica del español como lengua extranjera del Instituto Cervantes de Río de Janeiro. Disponível em: http://cvc.cervantes.es/ensenanza/biblioteca_ele/publicaciones_centros/PDF/rio_2006/26_dasilva.pdf. Acesso em: 10 out. 2016.

SILVA, B. S. Nível de qualidade em atendimento de Service Desk em Espanhol e emprego de características linguísticas: uma pesquisa baseada em corpus. Sáo Paulo: PUCSP, 2013. 178 f. Dissertaçấo (Mestrado em Linguística Aplicada e Estudo da Linguagem), LAEL, Universidade Católica de Săo Paulo, Săo Paulo, 2013.

SERIKAKU, H. Padrōes de usos de pronomes átonos lexicalizados no espanhol: um estudo baseado na Linguística de Corpus.Sâo Paulo: PUC-SP, 2014. 181 f. Dissertaçăo 
(Mestrado em Linguística Aplicada e Estudo da Linguagem), LAEL, Universidade Católica de Sáo Paulo, Sáo Paulo, 2014.

SINCLAIR, J. Reading Concordances: an introduction.London: Longman, 2003.

SINGLETON, D. Language and the lexicon an introduction.London: Oxford UniversityPress, 2000.

STEIN, C. M. S. A Linguística de Corpus e os heterosseânticos no par de línguas espanhol/ português. Revista Escrita, Gávea, n. 17, pp. 1-20, 2013. Disponível em: http://www.maxwell.vrac.puc-rio.br/22340/22340.PDF. Acesso em: 01 out. 2016.

TORREGO, L.G.Gramática didáctica del español. Sāo Paulo: Ediçōes SM, 2005.

VIANA, V. Linguística de Corpus: Conceitos, Técnicas e Análises. In: VIANA, V.; TAGNIN, S. (Orgs). Corpora no ensino de línguas estrangeiras. Sāo Paulo: Hub Editorial, 2010. pp. 25-95. 